REVISTA DE DERECHO UNED, NÚM. 24, 2019

\title{
EXCEPCIONES AL RÉGIMEN DE INCOMPATIBILIDADES DE LOS EMPLEADOS PÚBLICOS
}

\author{
EXCEPTIONS TO THE PUBLIC EMPLOYEES' \\ INCOMPATIBILITIES REGIME
}

Carmen Seoane Bouzas

Doctoranda en Derecho por la UNED

Resumen: La finalidad de este trabajo es mostrar un análisis de las disfunciones normativas y prácticas que se presentan en la aplicación jurídica de las excepciones al régimen de incompatibilidades de los empleados públicos del art. 19 de la Ley 53/1984, de 26 de diciembre, de incompatibilidades del personal al servicio de las Administraciones Públicas (LI) y en la escasa normativa de desarrollo. Analizaremos los aspectos más controvertidos de las excepciones y abordaremos la delimitación de los conceptos jurídicos indeterminados, deteniéndonos más en el análisis de la excepción referida a la administración del patrimonio personal y familiar, por constituir una especie de "cajón de sastre» al que los empleados públicos recurren cuando son sorprendidos en el ejercicio de una segunda actividad, para finalmente realizar una serie de propuestas de cambio normativas en aras de garantizar la coordinación de los principios reguladores del régimen jurídico de los servidores públicos con el ejercicio de una segunda actividad. Finalmente, trataremos algún caso concreto referido a los funcionarios con habilitación de carácter nacional, que se plantea en el día a día, exceptuado de esta ley por el peculiar régimen que rodea a estos funcionarios.

Abstract: The purpose of this paper is to show an analysis of the normative and practical dysfunctions that are presented in the legal 
application of the exceptions to the public employees' incompatibilities regime of art. 19 of the Law 53/1984, of December 26, of incompatibilities of the Public Administrations' service staff (LI) and in the scarce regulations of development. We will analyze the most controversial aspects of the exceptions and address the delimitation of indeterminate legal concepts, expanding more in the analysis of the exception referred to the administration of personal and family assets, as a kind of "hodgepodge» to which public employees resort when they are caugth in the exercise of a second activity, to finally make a series of proposals for normative change in order to guarantee the coordination of the regulatory principles of the legal regime of public servants with the exercise of a second activity. Finally, we will deal with a specific case referred to officials with national qualifications, which arises in the day to day, excepted for this law by the peculiar regime that applies to these officials.

Recepción original: 23/01/2019

Aceptación original: 31/01/2019

Sumario: I. Principios generales. II. La compatibilidad, la incompatibilidad y las actividades exceptuadas de la Ley 53/84, de 26 de diciembre, de incompatibilidades del personal al servicio de las administraciones públicas. III. Las actividades derivadas de la administración del patrimonio personal. III.A. Delimitación del concepto jurídico indeterminado "administración del patrimonio». III.B. La actividad a través de una sociedad. III.C. El ejercicio del cargo de administrador. IV. La actividad académica. V. Otros supuestos de exención. VI. Otras situaciones referidas a Funcionarios con habilitación de carácter nacional. VI.A. La acumulación de otro puesto reservado. VI.B. El ejercicio como letrado del ayuntamiento.VII. Conclusiones. Bibliografía.

\section{PRINCIPIOS GENERALES}

La Ley 53/1984, de 26 de diciembre, de incompatibilidades del personal al servicio de las Administraciones Públicas parte, como principio fundamental, de la dedicación del personal al servicio de las Administraciones Públicas a un solo puesto de trabajo, sin más excepciones que las que demande el propio servicio público, respetando el ejercicio de las actividades privadas, que no puedan impedir o menoscabar el estricto cumplimiento de sus deberes o comprometer su imparcialidad o independencia. La Ley viene a cumplimentar, en esta materia, el mandato de los artículos 103.3 y 149.1.18 de la Constitución. 
El fin que pretende el legislador con la regulación del régimen de incompatibilidades es implementar la exigencia a los servidores públicos de un esfuerzo testimonial de ejemplaridad ante los ciudadanos, constituyendo en este sentido un importante avance hacia la solidaridad, la moralización de la vida pública y la eficacia de la Administración.

De manera que destaca, por un lado, según OLÍAS DE LIMA GETE, el componente ético, ya que «el funcionario debe salvaguardar los supremos intereses de los poderes públicos ${ }^{1}$ », garantizándose la imparcialidad y la defensa del interés público en la actuación del personal al servicio de la Administración Pública. En la misma línea se pronuncia la jurisprudencia del Tribunal Supremo al afirmar que la legislación de incompatibilidades pretende evitar la existencia de contactos o áreas de actividades coincidentes que puedan dar lugar a los medios y facultades concedidas al funcionario por razón de su cargo, para ser utilizados en provecho particular, pudiendo venir en perjuicio del interés público o, por lo menos, del prestigio que por su independencia debe rodear al funcionario ${ }^{2}$.

Por otro lado, encontramos en la normativa de incompatibilidades un fundamento económico laboral, ya que se redistribuyen los recursos de trabajo existentes, influyéndose así en la política social y económica, ya que esos otros puestos podrán ser desempeñados por terceros y no por los empleados públicos. La jurisprudencia del $\mathrm{TC}^{3}$ ha considerado que tratar de alcanzar el objetivo de una mejor distribución del empleo público con el consiguiente efecto final favorable para quienes se hallen en una posición menos ventajosa en el mercado de trabajo, no sólo no es contrario a la Constitución, sino ajustado a ésta, aunque de ello puedan derivarse, como es obvio, restricciones para quienes disfrutan, o pudieran hipotéticamente disfrutar, de más de un empleo.

Pero también, el régimen de incompatibilidades persigue el cumplimiento del principio de eficacia, en cumplimiento del art. 103.1 en relación con el 1.1 de la Constitución, ya que este principio ha de presidir la organización y la actividad de la Administración, por lo que el legislador ha de tenerlo en cuenta al establecer el régimen de incompatibilidades. También otros principios inspiradores del funcionamiento de la Administración como la cali-

${ }^{1}$ OLÍAS DE LIMA GETE, B., «Las incompatibilidades de los altos cargos», Revista española de Derecho Administrativo, núm. 40-41, 1984, pág. 128.

2 STS de 14 de febrero de 1968.

3 STC de 2 de noviembre de 1989. 
dad de los servicios públicos, la racionalización del empleo público o la imagen de la Administración se han constituido más recientemente en base justificativa del régimen de incompatibilidades, así como los principios éticos enunciados en el Real Decreto Legislativo 5/2015, de 30 de octubre, por el que se aprueba el texto refundido de la Ley del Estatuto Básico del Empleado Público (art. 53 TRLEBEP) referidos básicamente al cumplimiento del ordenamiento jurídico, abstención de conflicto de intereses y lealtad y buena fe en su actuación.

En definitiva, el régimen de incompatibilidades es una garantía previa para la gestión objetiva, e incluso eficaz, de los intereses generales.

Si bien debemos destacar que ante las medidas de contención de gastos de personal, llevadas a cabo por el Gobierno en los últimos años para paliar la actual coyuntura económica, reduciendo el déficit público sin menoscabar la prestación de los servicios públicos esenciales y mejorando la eficiencia de las Administraciones Públicas en el uso de los recursos públicos, con objeto de contribuir a la consecución del inexcusable objetivo de estabilidad presupuestaria, la Disposición adicional quinta del Real Decreto-ley 20/2012 $2^{4}$, de 13 de julio, de medidas para garantizar la estabilidad presupuestaria y de fomento de la competitividad, estableció la posibilidad de que los funcionarios de la Administración General del Estado pertenecientes a los Subgrupos A1 y A2 soliciten la reducción, a petición propia, del complemento específico para el ejercicio de una segunda actividad. Esta previsión vino a complementar el Acuerdo del Consejo de ministros de 16 de diciembre de 2011, por el que en términos similares se permitió solicitar la misma re-

4 «Disposición adicional quinta. Posibilidad de que los funcionarios de la Administración General del Estado pertenecientes a los Subgrupos A1 y A2 soliciten la reducción, a petición propia, del complemento específico.

1. Los funcionarios de la Administración General del Estado pertenecientes a los Subgrupos A1 y A2, incluidos en el ámbito de aplicación del Real Decreto 598/1985, de 30 de abril, podrán solicitar ante las órganos y unidades de personal con competencias en materia de personal de los Departamentos, Organismos Autónomos y Entidades gestoras de la Seguridad Social en los que estén destinados la reducción del importe del complemento específico correspondiente al puesto que desempeñan al objeto de adecuarlo al porcentaje al que se refiere el artículo 16.4 de la Ley 53/1984, de 26 de diciembre, de Incompatibilidades del Personal al Servicio de las Administraciones Públicas.

2. Se excluye de esta posibilidad a los funcionarios que ocupen puestos en Gabinetes de miembros del Gobierno y altos cargos de la Administración General del Estado, y a los que desempeñen puestos que tengan asignado complemento de destino de nivel 30 y 29 ». 
ducción a los funcionarios de la Administración General del Estado pertenecientes a los Subgrupos C1, C2 y E 5 .

PARADA VÁZQUEZ y FUENTETAJA PASTOR ${ }^{6}$ consideran una triple perspectiva de la incompatibilidad de los empleados públicos por la configuración legal y jurisprudencial que se ha ido perfilando: funcional, horaria y económica.

Por otra parte, la Ley no contempla una definición de «incompatibilidad», por lo que debemos acudir a la doctrina para acotar el término, y así SARMIENTO LARRAURI ${ }^{7}$ considera que la incompatibilidad hace referencia más bien al impedimento para desempeñar varios puestos de trabajo o cargos, omitiendo la nota, según MESEGUER YEBRA ${ }^{8}$ esencial, de «simultaneidad en el tiempo». Define la incompatibilidad como «aquella situación en la que se encuentra el funcionario que simultanea su puesto de trabajo con otro dentro de la Administración pública, al margen de la actividad encomendada en cuanto tal, o fuera de ella, percibiendo una remuneración en ambos puestos de trabajo».

El art. 1 de la LI en su apartado primero establece como regla general la incompatibilidad de la simultaneidad de dos puestos de trabajo en el sector público; el apartado 2 hace referencia a la incompatibilidad económica y funcional, ya mencionada como uno de los principios de la Ley; y el apartado 3 establece la regla, tanto para las segundas actividades privadas como públicas, de que no impidan o menoscaben el estricto cumplimiento de los deberes del empleado público o comprometa la imparcialidad o independencia.

En este sentido la doctrina consolidada del $\mathrm{TS}^{9}$, tanto de la sala de lo contencioso como de la militar, ha establecido reiteradamente

5 «1. Los funcionarios de la Administración General del Estado pertenecientes a los Subgrupos C1, C2 y E incluidos en el ámbito de aplicación del Real Decreto 598/1985, de 30 de abril, podrán solicitar ante las órganos y unidades de personal con competencias en materia de personal de los Departamentos, Organismos Autónomos y Entidades Gestoras de la Seguridad Social en los que estén destinados, la reducción del importe del complemento específico correspondiente al puesto que desempeñan al objeto de adecuarlo al porcentaje al que se refiere el artículo 16.4 de la Ley 53/1984, de 26 de diciembre, de Incompatibilidades del personal al servicio de las Administraciones Públicas».

${ }^{6}$ PARADA VÁZQUEZ, R. y FUENTETAJA PASTOR, J., Derecho de la función pública, Thomson reuters, Civitas, Navarra, 2017.

7 SARMIENTO LARRAURI, J. I., "Las incompatibilidades para el personal al servicio de las Administraciones Públicas», Actualidad Administrativa, núm. 41, 7 a 13 de noviembre de 1988, pág. 2401 a 2413.

8 MESEGUER YEBRA, J., El régimen de las incompatibilidades de los empleados públicos, Bosch, Barcelona, Segunda Edición, octubre de 2007, pág. 37.

9 STSJ M de 18 de marzo de 2010. 
que basta con que exista la posibilidad o potencialidad de que se produzca la misma, sin necesidad de que llegue a ser real o efectiva, en lo que se ha venido conociendo como áreas de coincidencia, para evitar que las facilidades y medios que puedan tener los funcionarios por razón de su cargo puedan influir en provecho particular y perjudicar el interés público, además de que se refuerza, de esta manera, el prestigio y credibilidad de los servidores públicos, predicándose objetividad e imparcialidad en su conducta ${ }^{10}$.

\section{LA COMPATIBILIDAD, LA INCOMPATIBILIDAD Y LAS ACTIVIDADES EXCEPTUADAS DE LA LEY 53/84, DE 26 DE DICIEMBRE, DE INCOMPATIBILIDADES DEL PERSONAL AL SERVICIO DE LAS ADMINISTRACIONES PÚBLICAS}

Respecto a las actividades públicas la LI parte en su art. 1.1 de una regla de carácter general que es la incompatibilidad, si bien existen las excepciones contempladas en el art. 3, que remite a los art. 5 y 6 , en relación a la actividad docente y sanitaria, miembros electos y a aquellos casos que se determinen por el Consejo de Ministros, y al art. 4 respecto a la actividad docente universitaria.

En estos casos es necesaria la previa y expresa autorización de compatibilidad, que no puede suponer la modificación de jornada de trabajo y horario de los dos puestos. Además en el apartado 2 del mencionado art. 3 se establece una prohibición de que estos puestos de trabajo referidos son incompatibles con la percepción de pensión de jubilación o retiro por derechos pasivos u otro régimen de la Seguridad Social, quedando en suspenso en esos casos las pensiones mientras dure el desempeño del puesto, con la excepción del ámbito laboral, que será compatible la pensión de jubilación parcial con un puesto de trabajo a tiempo parcial.

Respecto a la necesidad de obtener la autorización para estas segundas actividades públicas permitidas por la Ley debemos destacar que el legislador utiliza el término «autorización» y no el de «reconocimiento» o "declaración» que utiliza respecto a las segundas actividades privadas, y ello es debido a que la LI parte de una compatibilidad preexistente para las actividades privadas, que necesitan tan slo de una declaración o reconocimiento, y, por el contrario, respecto a las actividades públicas parte de una prohibición genérica, incluso podríamos decir que casi absoluta. De ahí que SÁN-

\footnotetext{
10 STS de 14 de febrero de 1968; STS de 26 de julio de 2018.
} 
CHEZ MORÓN ${ }^{11}$ y parte de la doctrina, con la que coincidimos plenamente, entiendan que la autorización de la segunda actividad pública no es un acto reglado, siempre en los supuestos establecidos por la LI, sino que en todo caso queda sujeta a que «razones de interés público» lo permitan, pudiendo denegarse motivadamente; y sin embargo, el reconocimiento de actividades privadas es un acto reglado, siempre que no se den los supuestos de prohibición y se cumplan las condiciones establecidas en la LI.

En relación a las actividades privadas la Ley establece en el art. 11 en conexión con el mencionado apartado 3 del art. 1, la prohibición de la realización de actividades al servicio de entidades o particulares que se relacionen directamente con el Departamento, Organismo o Entidad donde estuviera destinado, pretendiendo evitar las «áreas de coincidencia» y salvaguardar así la imparcialidad y cumplir con el principio de eficacia. Exceptuando las actividades particulares que, en ejercicio de un derecho legalmente reconocido, realicen para sí los directamente interesados.

Ante la indefinición del legislador la Jurisprudencia ha ido perfilando caso por caso cuándo existe y cuándo no esa relación directa. A este respecto debemos entender que no se da tal relación directa ${ }^{12}$ cuando, en el caso de un funcionario de administración local la actividad se ejerce en otro municipio, ya que no hay que identificar la relación directa con la semejanza entre actividades, sino a una relación concreta entre los específicos asuntos de que se ocupa el funcionario en la esfera pública y en la privada, ya que lo normal es que un profesional de un ámbito concreto se dedique a un mismo tipo de actividad, que es para lo que se ha preparado. Desde este punto de vista si un técnico interviene en un proyecto a título particular y se somete a consideración de algún trámite en el Departamento, Organismo o Entidad en el que trabaja existe un área de coincidencia que lo convierte en incompatible, pero si ese trámite se produce en el municipio de al lado no, siempre que no existan otras situaciones objetivas de incompatibilidad, como por ejemplo el conflicto de horarios o razones de tipo económicas.

Ya el Tribunal Supremo en el año $1983^{13}$, con ocasión de analizar la incompatibilidad de los arquitectos y de los aparejadores municipales para el ejercicio de actividades privadas dentro del término de los respectivos ayuntamientos, aludió al término «áreas de coin-

11 SÁNCHEZ MORÓN, M., Derecho de la Función Pública, Tecnos, Décima Edición, Madrid, 2017.

12 STSJ CLM de 13 de marzo de 2014.

13 STS de 27 de mayo de 1983. 
cidencia», estableciendo la innecesariedad de probar si se ha producido o no un provecho particular en perjuicio del interés público cuando concurre una situación de incompatibilidad, ya que simplemente la expectativa y posibilidad de que los medios y facultades concedidas al funcionario por razón de su cargo puedan ser utilizadas hace que se produzca esa área de coincidencia. De esta forma, entiende el Alto Tribunal que se garantiza el prestigio de la Administración y la objetividad, imparcialidad e independencia del servidor público.

Dependiendo del ámbito territorial que abarquen las consecuencias de las funciones que desempeña el empleado público la restricción al ejercicio de otra actividad, por motivo de las áreas de coincidencia será más o menos amplia. Así, por ejemplo, en el caso de empleados en las CCAA, se da un área más amplia de coincidencia ${ }^{14}$, así en relación a la compatibilidad del ejercicio del puesto de funcionario de la Consejería de Industria y la actividad mercantil de instalación de plantas fotovoltaicas, existe un nexo de carácter potencial entre las competencias del organismo y la actividad privada del funcionario y de su mercantil, que pone en peligro el mantenimiento de la objetividad e imparcialidad del funcionario, que viene realizando tareas de informe técnico, gestión, coordinación o elaboración de propuestas de resolución, participando, de esta forma, en la sustanciación de esos expedientes de autorización.

El legislador ha querido establecer, art. 12, una serie de actividades en todo caso incompatibles con el ejercicio de cualquier puesto de la función pública: el desempeño de actividades privadas en los asuntos en que esté interviniendo o lo haya hecho en los dos últimos años por razón de su puesto público y las prestadas a personas a quienes se esté obligado a atender en el desempeño de las funciones públicas, la pertenencia a Consejos de Administración y demás organismos que tengan una actividad directamente relacionada con las que gestione el Departamento, Organismo o Entidad en que preste sus servicios el personal afectado, el desempeño de cargos en empresas o sociedades concesionarias y similares y la participación superior al 10 por 100 en el capital de las Empresas o Sociedades.

También en el art. 14 hace mención de forma genérica a actividades profesionales, laborales, mercantiles o industriales (que no son de lista cerrada), que sí serán compatibles (aspecto formal) en caso de darse, además, otros requisitos (ámbito material en su aspecto

14 STSL CL de 1 de marzo de 2013. 
económico, horario y de no dependencia con el departamento donde el funcionario presta sus servicios), y para las cuales habrá que solicitar la declaración de compatibilidad ante el órgano competente de la administración.

El legislador (art. 19) también ha considerado, con mayor o menor precisión, una serie de actividades exentas de solicitud de compatibilidad, por tanto de libre ejercicio para el funcionario, siempre y cuando la imparcialidad no se vea comprometida y no afecte al horario de trabajo, y que trataremos de pormenorizar en los siguientes apartados de este trabajo:

— Las derivadas de la administración del patrimonio familiar.

- Dirección de seminarios o el dictado de cursos o conferencias en centros oficiales de formación de funcionarios.

- Participación en tribunales de selección.

- Participación del personal docente en exámenes, pruebas o evaluaciones distintas a las que habitualmente les corresponda.

- El ejercicio del cargo de Presidente, Vocal o miembro de juntas rectoras de Mutualidades o patronatos de funcionarios, siempre que no sea retribuido.

- La producción y creación literaria, artística, científica y técnica y las publicaciones.

- Participación ocasional en coloquios y programas.

— La colaboración y asistencia ocasional a Congresos, seminarios, conferencias o cursos de carácter profesional.

Finalmente, señalar que el incumplimiento de las normas sobre incompatibilidad se contempla en el TRLEBEP y en la normativa de desarrollo, Real Decreto 33/1986, de 10 de enero, por el que se aprueba el Reglamento de Régimen Disciplinario de los Funcionarios de la Administración del Estado, sin perjuicio de lo regulado en la normativa autonómica para los empleados de la respectiva Comunidad Autónoma, como infracción muy grave o grave (art. 95). Y podrá tener como consecuencia para el empleado público la separación del servicio, la suspensión de funciones o el traslado con cambio de residencia ${ }^{15}$.

15 Art. 14 y ss. del Real Decreto 33/1986, de 10 de enero, por el que se aprueba el Reglamento de Régimen Disciplinario de los Funcionarios de la Administración del Estado. 


\section{LAS ACTIVIDADES DERIVADAS DE LA ADMINISTRACIÓN DEL PATRIMONIO PERSONAL O FAMILIAR}

Se establece esta excepción en el apartado a) del art. 19 de la LI, si bien no se define en ningún precepto de la misma qué ha de entenderse por tal administración.

\section{III.A. Delimitación del concepto jurídico indeterminado «administración del patrimonio»}

El legislador establece un concepto jurídico indeterminado para recoger la exención de actividades derivadas de la «administración del patrimonio personal o familiar», por tanto habremos de acudir a la jurisprudencia, la cual tampoco es clara en muchos de los casos, para delimitar qué se ha de entender por tal administración, resultando difícil sentar pautas generales de delimitación de tal concepto jurídico, ya que es inevitable el análisis de la actividad concreta objeto del expediente sancionador o denegación de la compatibilidad impugnadas. Resultando la casuística muy variada, y además, como señala el TSJ PV en la sentencia de 15 de febrero de 2007, «la problematicidad para el intérprete de casos como el presente puede acentuarse hasta niveles difícilmente resolubles».

Consideramos conveniente el análisis conjunto de este término con la fórmula a través de sociedad analizada en el siguiente apartado, por ser ésta la forma más frecuente, a la vez que controvertida, en la que se suele ejercer este tipo de actividad de administración del patrimonio.

\section{III.B. La actividad a través de una sociedad}

A continuación se realiza una examen de la jurisprudencia que nos permitirá concluir unas notas sobre qué debemos entender por administración del patrimonio personal o familiar, bien sea mediante gestión directa del mismo o a través de una sociedad, sea del tipo que fuese.

Por un lado, la jurisprudencia del Tribunal Supremo, ha venido sentenciando, ante casos que consideramos flagrantes de situaciones de incompatibilidad, cuyos afectados pretendían cobijarse de en esta infedinida excepción de "administración del patrimonio familiar»: 
- En un caso en que un guardia civil constituye una comunidad de bienes con su esposa dedicada a la gestión de fincas, seguros, empresa de servicios y construcción e inmobiliaria la Sala de lo Militar del Tribunal Supremo ${ }^{16}$ considera que, a pesar de que pudiera pretender tener como finalidad ayudar a su esposa, la actividad rebasa ese hipotético objetivo y se adentra de lleno en la gestión comercial, además de que dicha actividad se desarrollaba en el mismo término municipal en que el guardia prestaba servicio, produciéndose ese riesgo de merma de la imparcialidad del funcionario que la Ley trata de neutralizar con la prohibición del ejercicio o desempeño de actividades privadas. Sin que, para incurrir en la incompatibilidad, sea preciso que la actividad sea remunerada directamente ${ }^{17}$, ya que la razón de una incompatibilidad no radica en la remuneración, sino en la perturbación que su desempeño puede producir en las funciones que la Guardia Civil ha de ejercer. Además, precisa el Tribunal Supremo, que es fundamental distinguir, para delimitar este concepto jurídico indeterminado, entre las actividades de mantenimiento y conservación de lo que ya es propio, es decir, de bienes y recursos ya integrados en el patrimonio del titular, y aquellas en que la inicial inversión lleva aparejados trabajos, gestiones o actividades laborales, mercantiles o industriales encaminados, lejos de a esa conservación y mantenimiento, a su creación, incremento o multiplicación, cuyo ejercicio sí que necesita de la previa obtención de autorización administrativa.

- Otra situación se enjuicia ${ }^{18}$ en el caso de unos guardias civiles que constituyen una sociedad para alquilar un negocio de bar, considerando el Tribunal Supremo, en la línea ya sentenciada, que la actividad de gestionar el patrimonio familiar es incompatible con la realización de trabajos, gestiones o actividades laborales, mercantiles o industriales que tienden a su creación, incremento o multiplicación a base de alguna forma de ocupación en la empresa o negocio de que se trate, contrarios a una mera gestión económica.

- Otro caso, que nos ayuda a delimitar más el concepto, enjuicia $^{19}$ a un letrado de las Cortes Generales que pertenecía

16 STS (Sala de lo Militar) de 14 de septiembre de 2009.

17 STS (Sala de lo Militar) de 23 de enero de 2006, en los mismos términos la de 10 de enero de 2002 y 4 de julio de 2003.

18 STS (Sala de lo Militar) de 21 de septiembre de 2009.

19 STS de 30 de abril de 2013. 
a varias sociedades y era administrador de algunas, y había desplegado una importante y continuada actividad empresarial desde el conjunto de sociedades de su propiedad o de las que era dueño mayoritario. Considerándose tal conducta un ejercicio de la libertad de empresa, alejado del mantenimiento y administración del patrimonio personal y familiar, sino que se orientó a incrementar el patrimonio propio mediante la dirección de esas sociedades y su intensa actuación económica, resultando que, aparte de letrado de las Cortes Generales era un empresario en plena actividad.

La Audiencia Nacional ${ }^{20}$ se pronuncia en similares términos siguiendo la doctrina establecida por el TS en relación a lo que se considera actividades de mantenimiento y conservación de bines y recursos ya integrados en el patrimonio del titular.

Y en los Tribunales Superiores de Justicia podemos encontrar sentencias similares, aunque en algunos casos aportan algún matiz más a tener en cuenta en la delimitación del concepto. Es significativa a este respecto la STSJ del País Vasco ${ }^{21}$ que analiza el caso de un Ertzaintza que ayudaba en la empresa de su cónyuge (heredada de su madre) de trabajos de construcción, habiéndose dado de alta en autónomos. Consciente el Tribunal de que no existe una separación clara entre la mera conservación o mantenimiento financiero de un activo patrimonial y actividades empresariales comerciales o industriales que objetivamente supongan prestar servicios o producir bienes para el mercado, generando valor añadido y lucro adicional, considera que siempre que no estén a su vez comprendidas en los casos límites del articulo 12.1 no hay elementos ciertos para excluirlo de la fórmula del precepto de exención comentado, ya que el patrimonio empresarial, como realidad jurídica y económica incuestionable, no se administra ni gestiona como el patrimonio financiero o inmobiliario. Por tanto, se ha de realizar una interpretación caso por caso par determinar qué actividades de tipo industrial precisarían de reconocimiento y cuáles se podrían ejercer libremente. El Tribunal descarta las mercantiles gestoras, pero lo que no está claro es que el legislador haya querido excluir del ámbito del art. 19 las tareas de colaboración industrial en un pequeña empresa o negocio familiar efectuando, en tiempo libre, operaciones propias de trabajador manual. Teniendo en cuenta, además que en el expediente

20 SAN, Sala de lo Contencioso-administrativo, de 16 mayo de 2006; SAN, Sala de lo Contencioso-administrativo, de 4 de octubre de 2018;

21 STSJ PV de 15 de febrero de 2007. 
disciplinario tramitado no ha quedado acreditado que el funcionario realizase actividad mercantil alguna ni el empleo de apoderamientos, cargos gestores, u otro tipo de indicativo de operaciones que otorguen sustantividad a su actuación, finalmente considera que su actividad ante esta indefinición y falta de prueba en el expediente no se puede encuadrar en una incompatibilidad sujeta a previa autorización, ya que ha llevado a cabo tareas auxiliares dentro de la empresa como la conducción del camión y la carga y descarga del mismo y procede a la anulación de la sanción impuesta.

Llegados a este punto es preciso analizar las escasas sentencias de nuestros tribunales que contienen fallos estimatorios, pero que nos permiten conocer qué casos sí se consideran actividades de la administración del patrimonio personal y familiar, acercándonos a la delimitación del concepto jurídico indeterminado utilizado por el legislador desde la perspectiva del empleado público:

- La Audiencia Nacional ${ }^{22}$ en el caso de un policía nacional que colaboraba en la recaudación de diversas máquinas tragaperras, pertenecientes a la empresa propiedad de su esposa, en la que se limitaba a abrir el cajetín de cada una de ellas y a recoger el metálico, entendió que esta actividad estaba amparada por el concepto de administración del patrimonio personal o familiar al no tratarse del desarrollo de actividades laborales o profesionales, sino de un simple acto de percepción de cantidades dinerarias destinadas a ingresar en el patrimonio de la empresa de su esposa.

- El Tribunal Superior de Justicia de Cataluña ${ }^{23}$ al analizar el recurso de un funcionario del Cuerpo de Técnicos Especialistas, Cuerpo Servicios Penitenciarios de la Generalitat, socio fundador y mayoritario con su esposa de una mercantil dedicada a la formación, en situación de baja, considera no vulnerada la normativa de incompatibilidades porque la actividad no estaba directamente relacionada con la desempeñada en el departamento, organismo o entidad pública en la que presta servicios el funcionario.

- En el caso de un médico que solicita el complemento específico al estar excluida de compatibilidad el alquiler de viviendas de su patrimonio el Tribunal Superior de Justicia de Cataluña ${ }^{24}$

22 SAN, Sala de lo Contencioso-administrativo, de 29 marzo de 1999.

${ }_{23}$ STSJ CAT, Sala de lo Contencioso-administrativo, de 27 de marzo de 2000.

${ }^{24}$ STSJ M, Sala de lo Social, de 28 de abril de 2000; en términos similares STSPV, Sala de lo Social, de 20 de abril de 1998. 
consideró que era de aplicación el art. 19 en relación con el art. 12.1 de la Ley de incompatibilidades y por tanto la posibilidad de percibir el complemento específico o por exclusividad, con actividades de administración de patrimonio familiar, siempre que la actividad de ese negocio no esté directamente relacionada con las actividades que gestione el departamento - organismo o entidad en que presta servicios el personal afectado.

- La Audiencia Nacional ${ }^{25}$ en el caso de un funcionario de instituciones penitenciarias que ejercía de administrador de empresa familiar patrimonial, dedicada al «arrendamiento, administración, enajenación de edificaciones, fincas rústicas y urbanas en general, la realización de estudios, obras de urbanización y construcciones sobre las mismas, así como su explotación directa o indirecta» consideró que el hecho de que las tres operaciones llevadas a cabo por el funcionario como administrador de la empresa familiar no puede ser más gravoso que si las mismas se hubieran realizado por un particular para la administración de su patrimonio personal o el de sus ascendientes directos, ya que si no fuera así serían múltiples los funcionarios que podrán ser sancionados por realizar operaciones puntuales similares de compra venta con su patrimonio personal o cuando actuaran en representación de sus ascendientes, teniendo en cuenta que no se trata de una actividad continuada.

- Un Guardia civil solicita la compatibilidad para ejercer la actividad privada de administrador (en sustitución de su esposa) de una empresa familiar y se la deniegan, el Tribunal Superior de Justicia de Madrid ${ }^{26}$ va más allá y considera que la actividad se encuentra dentro del régimen de exenciones del art. 19.a) LI, que no establece una lista tasada o numerus clausus de supuestos, al margen de los cuales no sea posible autorizar compatibilidad alguna; por tanto, cuando no se encuentra el supuesto entre los enumerados en tal norma, puede, no obstante considerarse que la actividad sea compatible con el ejercicio de la actividad pública. Pero, además, nada indica el tenor literal

${ }^{25}$ SAN, Sala de lo Contencioso-administrativo, de 28 julio de 2005; en términos similares STSJPV, sala de lo Contencioso-administrativo, de 11 de febrero de 2008; y STS, sala de lo Militar, de 25 de enero de 2011.

${ }^{26}$ STSJ de Madrid, Sala de lo Contencioso-administrativo, de 30 abril de 2013; en términos similares STSJ de Madrid, Sala de lo Contencioso-administrativo, de 25 de febrero de 2013; y STSJ de Canarias, Sala de lo Contencioso-administrativo, de 11 de junio de 2013. 
de la norma ni su interpretación según el contexto, que por «administración de patrimonio personal» haya de excluirse concretamente la administración de una empresa propiedad del recurrente.

- Los jueces impugnan el Reglamento 2/2011 de la Carrera Judicial en el art. 326.1, letras h) e i), sobre sujeción de determinadas actividades a la previa concesión de compatibilidad, como el caso de la administración del patrimonio personal o familiar a que se refiere la letra a) del artículo 19 de la Ley 53/1984, bajo forma de sociedad o cualquier otro tipo de persona jurídica, así como de comunidades de bienes. El Tribunal Supremo ${ }^{27}$ considera que tal autorización es realmente una innovación reglamentaria del estatuto de jueces y magistrados, que establece un requisito inexistente en la LOPJ, produciéndose una extralimitación reglamentaria.

- El presidente de Baleares era administrador de empresa patrimonial de inmuebles y el Tribunal Superior de Justicia de Baleares $^{28}$ consideró que la titularidad y administración de una empresa sí puede formar parte del patrimonio personal o familiar y que no deriva en incompatibilidad, siempre que en el mismo no se realice más actividad de administración que la simple gestión de lo que ya es propio, sin una implicación u ocupación en la empresa en modo que exceda de la mera conservación de una empresa - obviamente generadora de recursos- ya integrada en el patrimonio personal.

De lo analizado podemos extraer las siguientes conclusiones en torno a la actividad de administración del patrimonio personal o familiar:

1) La introducción de la titularidad de empresa como supuesto de patrimonio personal o familiar exceptuado de la regla general, es admitida por la Jurisprudencia del Tribunal Supremo, pero con limitaciones. Debemos considerar que están incluidas dentro de tal actividad de administración las actividades de mantenimiento y conservación de bienes y recursos ya integrados en el patrimonio del titular, encuadrables propiamente en la administración o gestión de lo que ya es propio. Es decir, lo que se ha generado o se ha integrado en el patrimonio por otros medios distintos a la actividad mercantil o industrial,

27 STS, Sala de lo Contencioso-administrativo, de 19 de julio de 2013.

28 STSJ BAL, Sala de lo Contencioso-administrativo, de 11 de junio de 2014. 
como puede ser una herencia, se puede mantener y conservar, actividad que se realizaría, por ejemplo, con el alquiler de bienes.

2) Aún así, no existe una separación tan drástica que pueda plasmarse en criterios tales como la mera conservación o mantenimiento financiero de un activo patrimonial, frente a actividades que generan valor añadido y lucro adicional, como las comerciales o industriales, siempre que no estén a su vez comprendidas en los casos límites del artículo 12.1.

3) Cuando no se deriva propiamente una actividad mercantil, y simplemente se está administrando el patrimonio con arreglo a lo antedicho, el participar o ser administrador de una sociedad, no excede del ámbito del art. 19.a) de la Ley 53/84.

4) La expresión patrimonio familiar abarca no sólo el patrimonio del cónyuge e hijos, sino también a los ascendientes por consanguinidad o afinidad.

5) El ejercicio regular de actividades «en que la inicial inversión va acompañada de trabajos, gestiones o actividades laborales, mercantiles o industriales, encaminados no al mantenimiento o conservación de bienes o recursos ya integrados en el patrimonio del propio titular, sino que tienden a su creación, incremento o multiplicación a base de alguna forma de ocupación en la empresa de que se trate» precisarán de la previa obtención de la correspondiente autorización administrativa. De manera que las actividades mercantiles gestoras necesitan compatibilidad.

6) Las actividades laborales o profesionales necesitan autorización de compatibilidad, al estar excluidas por su propia definición de la administración del patrimonio, bien sea el personal, bien sea el familiar.

\section{III.C. El ejercicio del cargo de administrador}

El ejercicio del cargo de administrador de una empresa que se dedique a la administración del patrimonio personal o familiar podría entrar en contradicción con lo establecido en el art. 14 LI ${ }^{29}$, que

29 «Artículo 14

El ejercicio de actividades profesionales, laborales, mercantiles o industriales fuera de las Administraciones Públicas requerirá el previo reconocimiento de compatibilidad...». 
requiere la solicitud de compatibilidad para el ejercicio, sin más concreción, de actividades industriales o mercantiles.

Una vez más debemos de acudir a la jurisprudencia para aproximarnos a cuándo ha de solicitarse la compatibilidad en caso de ejercer un cargo de administrador. Existen sentencias contradictorias, por tanto, va a depender de la finalidad de la sociedad y del concepto de patrimonio personal o familiar el que el ejercicio de tal cargo esté o no permitido sin previa solicitud de compatibilidad:

- En el caso de unos guardias civiles que constituyen una sociedad para alquilar un negocio de bar ${ }^{30}$ el Tribunal Supremo, por un lado, en torno a la participación como socio de nueva sociedad o una ya existente, considera que se trata de una actividad privada no necesitada de declaración de compatibilidad porque con ello el funcionario se limita a realizar una inversión de bienes que forman parte de su patrimonio personal o del patrimonio familiar, y por consiguiente ello se comprende entre las actividades exceptuadas de autorización por no quedar afectado, real o potencialmente, el bien jurídico que la normativa protege. Por otro lado, analiza el caso de desempeñarse el cargo de administrador, ya sea único o compartiendo el cargo con otros en régimen de solidaridad o con carácter mancomunado, por cuanto que el desempeño comporta el ejercicio de cometidos que pasan por la llevanza de la gestión y representación de la sociedad, y en este sentido determina que habrá que analizar si la sociedad se constituyó con la finalidad lógica de operar en el tráfico mercantil y, en su caso, si se produjo tal actuación, porque en caso contrario figurar como administrador de sociedad inactiva nada aporta respecto de la condición de socio, en cuanto se refiere a la lesión o puesta en peligro del bien jurídico objeto de tutela.

- En el ya mencionado caso del presidente de Baleares ${ }^{31}$, administrador único de empresa patrimonial, el Tribunal basándose en que es admitido por la jurisprudencia la compatibilidad cuando el cargo público ejerce en la empresa una actividad que se limita «al mantenimiento o conservación de recursos ya integrados en el patrimonio del propio titular», no ofrece dudas de que un empleado público podría arrendar inmuebles de su propiedad a título individual sin resultar incompatible con su actividad, por

30 STS, Sala de lo Militar, de 14 de septiembre de 2009; en términos similares SAN de 16 de mayo de 2006.

31 STSJ BAL, Sala de lo Contencioso-Administrativo, de 11 de junio de 2014. 
tanto, de la misma manera lo puede realizar si es propietario único de una sociedad patrimonial cuya única actividad es el arrendamiento de los inmuebles de su propiedad.

Sobre esta cuestión debemos tener en cuenta también lo interpretado por la Inspección General de Servicios de la Administración Pública respecto a administración del patrimonio familiar y personal contemplado por el legislador en el Criterio de Aplicación 13/I.87:

«a) La pertenencia al Consejo de Administración no supone incompatibilidad.

b) Define el patrimonio familiar como la propiedad de toda clase de bienes y titularidad de derechos de contenido económico (muebles o inmuebles).

c) La administración del patrimonio personal o familiar es compatible con la función pública por razón de excepción del régimen de incompatibilidades cuando se desarrolle de alguna de las siguientes formas: mediante la participación como consejero en consejos de Administración u Órganos rectores de Sociedades Anónimas o Sociedades de Responsabilidad Limitada en la medida que el nombramiento sea consecuencia de la titularidad de acciones...».

De manera que podemos concluir que si una empresa se constituye con la "finalidad de operar en el tráfico mercantil» el cargo de administrador se considera sujeto a compatibilidad, por el contrario si «tal actividad no se contempló desde el principio o bien que ésta no se produjo en ningún modo" y lo único que se realiza es la administración del patrimonio en los términos que venimos exponiendo, el figurar como "administrador de sociedad inactiva nada aporta respecto de la condición de socio». Por ello, tan sólo resultará una consecuencia más de la administración del patrimonio personal o familiar, en cuanto se refiere a la lesión o puesta en peligro del bien jurídico objeto de tutela.

En las sentencias referidas en este apartado y en el apartado anterior, por ej. la Sentencia de la Audiencia Nacional, Sala de lo Contencioso-administrativo, de 28 de julio de 2005, el tribunal admite como una consecuencia de la administración del patrimonio, mediante la forma jurídica de sociedad, el desempeñar el cargo de administrador, ya que si una vez sentado que la administración del patrimonio se puede realizar de forma individual o a través de sociedad, sea cual sea la forma que ésta revista, la exención del artículo 19.a) hay que entenderla absoluta, con la única excepción que el propio artículo sienta, que son los casos contemplados en el 
art. 12. Pues el acudir al art. 14 (El ejercicio de actividades profesionales, laborales, mercantiles o industriales fuera de las Administraciones Públicas requerirá el previo reconocimiento de compatibilidad) implicaría una remisión que el legislador no hace, y por tanto, se estaría limitando ex lege la exención del art. 19.a), más allá de las limitaciones contempladas en el referido art. 12, ya que "nada indica el tenor literal de la norma ni su interpretación según el contexto, que por "administración de patrimonio personal» haya de excluirse concretamente la administración de una empresa» (STSJ Madrid, de 30 de abril de 2013).

\section{LA ACTIVIDAD ACADÉMICA}

Dentro de este epígrafe trataremos de los apartados del art. 19 de la LI que están relacionados con el ámbito educativo, de la formación y académico:

- La dirección de seminarios o el dictado de cursos o conferencias en Centros oficiales destinados a la formación de funcionarios o profesorado, cuando no tengan carácter permanente o habitual ni supongan más de setenta y cinco horas al año, así como la preparación para el acceso a la función pública en los casos y formas que reglamentariamente se determine, (art. 19.b) LI): esta excepción tiene una limitación establecida por el art. 33 del RD 462/2002, de 24 de mayo, sobre indemnizaciones por razón del servicio, que regula las asistencias por colaboración en actividades de formación y perfeccionamiento y establece como límite exento las 75 horas anuales ${ }^{32}$.

- La participación en Tribunales calificadores de pruebas selectivas para ingreso en las Administraciones Públicas (art. 19.c) LI): A este respecto señalar que el art. 13.2 del RD 364/1995, de 10 de marzo, por el que se aprueba el reglamento general de Ingreso del Personal al Servicio de la Administración General del Estado, establece que la preparación durante los últimos cinco años para el acceso a la función pública implicará en todo caso incompatibilidad para formar parte de los órganos de selección del personal.

— La participación del personal docente en exámenes, pruebas o evaluaciones distintas de las que habitualmente les corresponda, en la forma reglamentariamente establecida (art. 19.d) LI):

32 STSJ Navarra, Sala de lo Contencioso-Administrativo, de 22 marzo 2001. 
- La participación ocasional en coloquios y programas en cualquier medio de comunicación social (art. 19.g) LI): el legislador, en coherencia con el sistema de incompatibilidades establecido en la Ley, exige la ocasionalidad, ya que el ejercicio habitual, constante y reiterado podría colisionar con los principios señalados de eficacia de la actividad correspondiente de la Administración y la dedicación del empleado público al puesto de trabajo.

- La colaboración y la asistencia ocasional a congresos, seminarios, conferencias o cursos de carácter profesional (art. 19.h) LI): este apartado no utiliza términos muy precisos en relación a las características que debe reunir la actividad para que pueda tener cabida en la excepción del régimen de incompatibilidades. Según la interpretación realizada en el dictamen en atención a consulta de 15 de junio de 1999 por la Comisión Superior de Personal del ministerio de Administraciones Públicas, en el que se cuestionaba la compatibilidad o incompatibilidad de la actividad de perito designado mediante nombramiento judicial, con la función desempeñada en un organismo público:

«...El apartado b) no ofrece dificultad alguna en su interpretación, sin que quepa hacer consideraciones que vayan más allá del contenido literal de dicho apartado, ya que establece de forma precisa los requisitos que debe reunir la actividad para que se pueda considerar exceptuada del régimen de incompatibilidades: que se trate de actividades correspondientes a la dirección de seminarios o dictado de cursos o conferencias en centros oficiales destinados a la formación de funcionarios o profesorado, que no tengan carácter permanente o habitual y que no supongan más de 75 horas al año.

...Por el contrario, el apartado h) del art. 19 de la Ley 53/1984 utiliza términos que no son tan precisos en la descripción de las características que debe reunir la actividad para que pueda tener cabida en el supuesto de exceptuación...».

La Jurisprudencia de nuestros tribunales se ha venido manifestando en sentido unívoco, por todas, la Sentencia Tribunal Superior de Justicia Extremadura, Sala de lo Contencioso-Administrativo, de 13 noviembre, F.J. 4. ${ }^{\circ}$, que en el caso de un funcionario de carrera destinado en la Asamblea que había venido desempeñando, sin autorización para ello, otro puesto en una Administración Pública, en concreto, el de profesor en la Escuela Universitaria de Enfermería de Mérida, entendió que el apartado h) exige que los congresos, seminarios, conferencias o cursos de carácter profesional sean ocasio- 
nales, cosa que no se daba en el funcionario, ya que realizó la actividad durante tres cursos consecutivos ${ }^{33}$.

De manera que el concepto de «colaboración» no puede abarcar la impartición de cursos prolongados, que constituyen el ejercicio de una actividad docente, que excede la excepción de dicho apartado, pudiéndose seguir a título orientativo el límite de las 75 horas establecido en el apartado $b$.

Por lo que respecta a qué ha de entenderse por curso profesional, la Dirección General de la Inspección, Simplificación y Calidad de los Servicios del Ministerio de Administraciones Públicas en el informe de 3 de mayo de 2001 señala «este carácter ha de alcanzar tanto a los destinatarios (debe ir dirigido a quienes ya tienen y ejercen una profesión), como al contenido y objeto del curso (posibilitar el mantenimiento del contacto deseable del funcionario con el mundo profesional al que pertenece en el ejercicio de sus funciones públicas)». Además, se exige la participación como asistente o colaborador, lo que significa tanto realizar parte de una actividad o tomar parte en la misma junto con otros, como la exposición individual de conferencias o charlas.

De forma que podemos concluir que al amparo de este apartado no se podrán, por ejemplo, impartir cursos universitarios de postgrado en las Universidades, tanto públicas como privadas, ni cursos de formación ocupacional, si no es bajo la previa solicitud y concesión de la compatibilidad.

\section{OTROS SUPUESTOS DE EXENCIÓN}

El art. 19 contempla también dos supuestos más de actividades no sujetas al régimen establecido en la Ley:

- El ejercicio del cargo de presidente, vocal o miembro de Juntas rectoras de Mutualidades o Patronatos de funcionarios: Esta excepción se recoge en el apartado f) del art. 19 LI, y debemos recordar en este punto que la incompatibilidad no debe entenderse sólo desde la perspectiva económica, sino también funcional, de forma que la imparcialidad puede verse afectada muchas veces por el mayor interés o beneficio que puede haber en el desempeño de una segunda actividad que excede de lo meramente pecuniario.

${ }^{33}$ En términos similares SAN de 8 de marzo de 2018. 
- La producción y creación literaria, artística, científica y técnica: Los Tribunales de Justicia han venido delimitando las labores que se entienden incluidas dentro de este apartado g) del art. 19 de la LI, así aunque la segunda actividad exija tareas comerciales y no sólo intelectuales no compromete el ejercicio de las funciones públicas:

- No existe limitación de las posibilidades privadas en todos esos órdenes o facetas de una publicación especializada, por entenderse que no comprometen la labor pública, incluso aunque se trate de la misma labor de publicación que exige tareas comerciales y no sólo intelectuales, no dándose aquí relación de empleo o de servicios ${ }^{34}$.

- En el caso de un funcionario que constituye una sociedad para la publicación literaria en la que participa una empresa con la que puede tener relación porque se relacionen directamente con las del Departamento, Organismo o Entidad en que trabaja el funcionario, la Audiencia Nacional considera ${ }^{35}$ que la gestión de la limpieza pública y protección ambiental, actividad desarrollada por la empresa pública, no está «directamente» relacionada con la producción, creación y edición de una publicación sobre medio ambiente urbano, pues sólo se da una identidad temática o de materia, pero la primera es de gestión de servicios y la segunda queda en el plano literario, científico, técnico o divulgativo; aquélla supone una organización empresarial compleja para el desarrollo y prestación del servicio en la ciudad, con lo que no está relacionado la segunda. Respecto a la prohibición legal de actividades privadas prestadas a personas a quienes se esté obligado a atender en el puesto, entiende que tampoco existe en el caso concreto por publicar o comercializar una enciclopedia sobre igual tema y con patrocinios de empresas contratistas, ya que se da este patrocinio de los atendibles pero no una actividad profesional prestada a ellos.

- Que se recoja en la Ley la salvedad de que la producción realizada como consecuencia de una relación de empleo o prestación o de prestación de servicios no afecta a la libertad de expresión, según el $\mathrm{TC}^{36}$.

34 STSJ de Sevilla, Andalucía, Sala de lo Social, de 2 octubre de 1998.

35 SAN, Sala de lo Contencioso-Administrativo, de 11 marzo 1999.

36 STC de 2 de noviembre de 1989. 


\section{OTRAS SITUACIONES REFERIDAS A FUNCIONARIOS CON HABILITACIÓN DE CARÁCTER NACIONAL}

\section{VI.A. La acumulación de otro puesto reservado}

Una de las formas de provisión de puestos de trabajo reservado a funcionarios con habilitación de carácter nacional reguladas en el reciente Real Decreto 128/2018, de 16 de marzo, por el que se regula el régimen jurídico de los funcionarios de Administración Local con habilitación de carácter nacional es la acumulación ${ }^{37}$.

De esta manera,en los supuestos contemplados en el artículo anterior de:

a) Comisión de servicios.

b) Suspensión provisional.

c) Excedencia por cuidado de hijos durante los dos primeros años.

d) Incapacidad temporal.

e) Otros supuestos de ausencia

Mientras dure la situación, previa solicitud del Alcalde o Presidente, y cuando no hubiese sido posible efectuar nombramiento provisional o comisión de servicios, imposibilidad que ha debido quedar lo suficientemente acreditada en el expediente se podrá acudir a este tipo de nombramientos, que le corresponderá a la Comunidad Autónoma o al Estado, según ese segundo puesto se encuentre en la misma Comunidad o en distinta.

37 «Artículo 50. Acumulaciones.

1. El órgano competente de la Comunidad Autónoma respectiva, en el ámbito de su territorio, podrá autorizar a los funcionarios de Administración Local con habilitación de carácter nacional que se encuentren ocupando un puesto de trabajo a ellos reservado, a desempeñar asimismo en otra Entidad Local las funciones reservadas a la misma u otra subescala o categoría, en los supuestos contemplados en el apartado 1 del artículo anterior y por el tiempo de su duración, cuando, previa solicitud del Alcalde o Presidente, no hubiese sido posible efectuar nombramiento provisional o comisión de servicios, imposibilidad que ha debido quedar lo suficientemente acreditada en el expediente.

Corresponde al Ministerio de Hacienda y Función Pública autorizar las acumulaciones cuando excedan del ámbito territorial de una Comunidad Autónoma.

l.../

Solo se podrá desempeñar un nombramiento en acumulación».

(c) UNED. Revista de Derecho UNED, núm. 24, 2019 
Al igual que en la legislación anterior se mantiene la percepción de una gratificación a cargo de la Entidad Local donde ejerce las funciones acumuladas de hasta el 30 por 100 de las retribuciones fijas, excluidos los trienios, correspondientes al puesto principal. Y ahora sí se limita el horario de ejercicio a que las funciones acumuladas deben ejercerse fuera de la jornada ordinaria del puesto de trabajo y a una acumulación. De esta manera se zanjan diferentes interpretaciones o interpretaciones a medida que venían haciendo algunos que acumulaban plazas vacantes y con horario indistinto en su plaza de origen o en la/s acumuladas en función de las «necesidades».

Consideramos que se trata de una situación que no está sometida a la LI, por un lado, porque el requisito para ejercerse es que se esté desempeñando un puesto de la subescala, es decir, si se está en alguna situación de excedencia o no se está en activo, es imposible el otorgamiento. Por otro lado, porque la retribución está limitada por la propia norma. Además, también debemos señalar la realidad en la que se suelen dar este tipo de nombramientos, que es para satisfacer las necesidades de los ayuntamientos demandantes, que por falta del titular en un período continuado, aunque no sea prolongado, comienzan a tener bloqueos o paralizaciones de sesiones de órganos colegiados, subvenciones, contratos, etc, no siendo casi nunca el beneficiado el funcionario, que por un tercio de su sueldo ha de asumir las responsabilidades y el trabajo de otro puesto en su tiempo libre, fuera de la jornada del primer puesto. Por último, debemos tener en cuenta otro detalle, que apoya la tesis que venimos defendiendo, y es que es necesaria la solicitud y conformidad de los dos alcalde y de otra administración, cuestión que no se da en los casos sometidos a autorización de compatibilidad de la LI, que requieren únicamente la autorización del pleno u órgano en que éste delegue del puesto desempeñado con carácter público.

Aún así, alguna Comunidad Autónoma, como es el caso de Galicia, pone en «la letra pequeña» de los condicionantes de la acumulación que otorga, que ha de solicitarse la compatibilidad. Cuestión que consideramos que no es procedente por los motivos expuestos, y que tampoco se ha concretado por parte de la Comunidad qué pleno ha de ser el que resuelva ni las consecuencias de paralización del efectivo inicio de tal acumulación (que muchas veces devendría ya en ineficaz por incorporación del titular antes de que los plenos resuelvan ) y, además, está incorporando un requisito no previsto por la norma específica que regula las acumulaciones. 


\section{VI.B. El ejercicio como letrado del ayuntamiento}

En función de lo establecido en el art. 551.3 de la LOPJ, cuyo tenor literal es el siguiente: «3. La representación y defensa de las comunidades autónomas y las de los entes locales corresponderán a los letrados que sirvan en los servicios jurídicos de dichas Administraciones públicas, salvo que designen abogado colegiado que les represente y defienda», los secretarios pueden realizar las funciones letradas en defensa de la entidad local en la que presten servicios.

El término de «letrado» es definido en el Diccionario de la Real Academia Española de la Lengua, como «abogado»; «jurista de una institución pública encargado de estudiar y preparar sus dictámenes y resoluciones» o "asesor jurídico permanente de una sociedad o empresa». De manera que reviste varias acepciones, sin que quepa encuadrarse exclusivamente dentro de la de despacho profesional.

El art. 544 de la misma norma establece que «La colegiación de los Abogados y Procuradores será obligatoria para actuar ante los Juzgados y Tribunales en los términos previstos en esta Ley y por la legislación general sobre Colegios profesionales, salvo que actúen al servicio de las Administraciones públicas o entidades públicas por razón de dependencia funcionarial o laboral.»; es decir, si relacionamos ambos artículos, nos encontramos con que, por una parte, el 551.3, permite a las entidades locales la designación de abogado colegiado que les represente y defienda; mientras que, por la otra, el art. 544, señala que la colegiación será obligatoria para actuar ante los Juzgados y Tribunales, «salvo que actúen al servicio de las Administraciones públicas» $\mathrm{y}$ "por razón de dependencia funcionarial y laboral».

Al respecto también se pronuncia la Ley 34/2006, de 30 de octubre, sobre el acceso a las profesiones de Abogado y Procurador de los Tribunales, en su Disposición Adicional Tercera, dedicada expresamente al "Ejercicio profesional de los funcionarios públicos.», que viene a corroborar el criterio expuesto, de innecesariedad de colegiación, cuando señala que el personal al servicio del Estado y Administraciones Públicas en su actuación ante Juzgados y Tribunales para el desempeño de las funciones propias del cargo se regirá por lo dispuesto en el artículo 551 de la Ley Orgánica 6/1985, de 1 de julio, del Poder Judicial, y demás legislación aplicable, y sin que en ningún caso le sea exigible la obtención del título regulado en dicha ley.

Añadiendo, expresamente el apartado n. ${ }^{\circ} 2$, de dicha Disposición Adicional: 
«2. Los funcionarios públicos que hayan accedido a un cuerpo o escala del grupo A en su condición de licenciados en Derecho estarán exceptuados de obtener el título de abogado o el título de procurador de los tribunales a los efectos descritos en el artículo 1 de esta ley, siempre que desempeñen funciones de asistencia letrada o asesoramiento jurídico».

Finalmente, tampoco podemos olvidar la emblemática Sentencia de la Audiencia Territorial de Oviedo, de 28 de abril de 1988 que, al referirse a la defensa judicial por parte de los secretarios, de forma rotunda y categórica, señala:

«...estos Letrados (Secretarios de Ayuntamiento) para representar y defender a sus respectivas Administraciones no es necesario que se hallen colegiados, pues se hallan en la misma situación que los Letrados de los servicios jurídicos del Estado y además porque la Ley cuando quiere que se trate de Abogados colegiados así lo dice expresamente, en este sentido el art. 447 citado, pues de lo contrario sería innecesaria la referencia a Abogado colegiado que en el mismo se contiene; en el mismo sentido cabe señalar que si bien en el art. 10 LEC y en el art. 33 de LJ se exige que los litigantes sean dirigidos por Abogado habilitado legalmente para ejercer su profesión, condición que le viene conferida por su colegiación, éste no es el único modo de habilitación para el ejercicio de la Abogacía, pues el art. 3 de la Ley de Colegios Profesionales, de la que el Estatuto General de la Abogacía, aprobado por RD. de 24-07-1982, constituye parte integrante de su desarrollo, señala como finalidad de los Colegios Profesionales la ordenación del ejercicio de las profesiones correspondientes, sin perjuicio de la competencia de las Administración pública por razón de la relación funcionarial, lo que permite sostener que en determinadas situaciones no son de aplicación o pueden ceder exigencias establecidas con carácter general, como tiene dicho el Tribunal Constitucional en su Sentencia 69/85 de 30 de mayo, excepción que asimismo se recoge en el art. 439.2 de LOPJ, al afirmar que será obligatoria la colegiación de los Abogados y Procuradores para actuar ante Juzgados y Tribunales, salvo que actúen al servicio de las Administraciones Públicas por razón de dependencia funcionarial o laboral, de tal forma que la relación que le vincula con los entes públicos a los que defiende le habilita para el ejercicio de la Abogacía dentro de la esfera administrativa a la que pertenece, llevando a cabo una actividad de defensa de los intereses de ésta de una forma ocasional y determinada, actividad que no se corresponde con el ejercicio habitual de la Abogacía con despacho abierto al público para la cual sí precisaría la correspondiente inscripción en el Colegio de Abogados, por lo que cabe afirmar que los Letrados pertenecientes a los servicios jurídicos de las Comunidades Autónomas y de los Entes locales no precisan para actuar ante los organismos judiciales de otra habilitación que la de su nombramiento y toma de posesión. La otra cuestión que se suscita consiste en determinar si el Secretario General Letrado de un Ayuntamiento puede entenderse integrado o no en el servicio jurídico del correspondiente 
Ente Local al que se halla adscrito, siendo de destacar que entre sus funciones se halla la del asesoramiento legal a la Corporación, a su Presidente y a las Comisiones, según el art. 162 TRRL, el informe previo a los acuerdos para el ejercicio de acciones necesarias para la defensa de los bienes y derechos de las Entidades locales, señalando en su apartado 4 que en la representación y defensa se estará a lo dispuesto en la LOPJ, señalando en su art. 166 que nada impide la asignación de otras funciones distintas o complementarias, entre las que puede hallarse la defensa ante los Tribunales de sus intereses, como se adoptó en el acuerdo del Ayuntamiento Pleno que ratificó el de la Comisión de Gobierno, que habia dispuesto que fuera su Secretario General quien se hiciera cargo de la representación y defensa de la Corporación, por lo que no cabe hablar de falta de capacidad para representar ni de falta de habilitación legal para actuar, pues aquélla le vino conferida por la propia Corporación y ésta por su condición de funcionario que actúa al servicio de la Administración Pública».

Se trata, a nuestro juicio, de otro supuesto de excepción de compatibilidad, ya que la habilitación para representar en juicio en este caso, al funcionario con habilitación de carácter nacional, secretario o secretario-interventor, le viene asignada precisamente por ser funcionario con competencias de informe jurídico al servicio de la propia corporación a la que va a defender, de manera que no es necesaria solicitud ni compatibilidad alguna, aunque a los abogados en ejercicio les cueste diferenciar este matiz del ejercicio profesional con despacho que ellos ejercen.

Consideramos que sería necesario para quedar acreditada la voluntad de la corporación, con la conformidad del funcionario, un acuerdo plenario de creación el servicio jurídico dentro de la organización municipal y la personación en juicio a través del acuerdo del órgano competente para ello, generalmente alcaldía, y en caso de interposición de recursos el acuerdo del órgano competente en función d ella delimitación de competencias establecido en los art. 21 y 22 de la LRBRL.

\section{CONCLUSIONES}

De todo lo analizado podemos concluir que el régimen jurídico de incompatibilidades recogido en la Ley 53/1984, de 26 de diciembre, de Incompatibilidades del personal al Servicio de las Administraciones Públicas, y en especial las situaciones exceptuadas del art. 19, generan no pocos inconvenientes interpretativos de cara a una aplicación certera y coherente de la norma, ya que aparte de la parquedad de la regulación apenas se alcanza a prever una mí-

(C) UNED. Revista de Derecho UNED, núm. 24, 2019 
nima parte de las situaciones de hecho que hoy en día, tras más de 30 años de vigor de la norma, se han venido planteando, poniéndose de manifiesto las carencias e indefinición de la Ley. A ello hay que añadir la práctica unánime inexistencia de desarrollo normativo de las Comunidades Autónomas, que ha venido a intensificar las carencias de tal regulación, a la vez que creado disparidad de criterios interpretativos, si además atendemos a la gran cantidad de municipios existentes en España, que a falta de mayores concreciones de la norma también utilizan su criterio interpretativo.

Por lo que se hace necesario acudir frecuentemente a los principios y directrices de la misma y en especial al principio que rige la Ley que es el de la incompatibilidad absoluta, el cual a raíz de los acontecimientos económicos y las reformas constantes en materia de personal para la contención del gasto (Real Decreto-ley 20/2012, de 13 de julio, de medidas para garantizar la estabilidad presupuestaria y de fomento de la competitividad), está perdiendo fuerza y razón de ser, poniéndose en entredicho tal premisa nuclear del régimen de incompatibilidades.

No obstante, la delimitación de los conceptos jurídicos indeterminados establecidos a los largo de los apartados del art. 19 ha venido realizándose por nuestros tribunales de justicia a propósito de casos concretos del ejercicio de una segunda actividad.

Por ello, convendría establecer una serie de pautas que podrían ser consideradas en la siguiente regulación del régimen de incompatibilidades:

1) Se debería proceder a una regulación integradora del régimen de flexibilización llevado a cabo con las últimas reformas legales con ocasión de la situación económica y contención del gasto público, de forma concisa y clara, para paliar así, de una vez por todas, la situación de hecho de muchos empleados públicos.

2) El apartado a del art. 19 ha de recoger lo establecido por la jurisprudencia de los tribunales, bien admitiendo y contemplando como exención del sometimiento a reconocimiento de compatibilidad el ejercicio de cargo de administrador cuando provenga de la propia administración del patrimonio personal o familiar, o bien exigiendo el reconocimiento.

3) Han de delimitarse en la propia ley las condiciones para que una actividad sea considerada administración del patrimonio o ejercicio de una actividad mercantil o industrial. 
4) Las actividades académicas de los apartados g) y h) han de ser igualmente delimitadas, estableciéndose un número máximo de horas e incluso porcentaje retributivo, hasta el cual el empleado público esté exento de solicitar la declaración de compatibilidad.

Por otra parte, una vez actualizada la regulación, se deberían de unificar y endurecer los controles por parte de la Administraciones Públicas sobre las situaciones de incompatibilidad no autorizadas con el fin de garantizar los principios inspiradores del régimen jurídico de la incompatibilidad.

\section{BIBLIOGRAFÍA}

BoIX ReIG, V., Régimen jurídico de la organización municipal. Estatutos del Concejal y del funcionario, Trivium. 1. a edición.

JimÉnEZ AsEnsio, R., «El personal directivo en la Administración Local», Estudios de Relaciones Laborales, Diputación de Barcelona, mayo 2009.

Lorenzo de Membiela, J. B., Incompatibilidades de los Funcionarios Públicos, Thomson Reuters, Ed. Aranzadi, Navarra, 2011.

Meseguer Yebra, J., El régimen de las incompatibilidades de los empleados públicos, Bosch, Barcelona, Segunda Edición, octubre de 2007, pág. 37.

Olías de Lima GeTE, B., «Las incompatibilidades de los altos cargos», Revista española de Derecho Administrativo, núm. 40-41, 1984, pág. 128.

Palomar Olmedo, A. y otros, Comentarios a la Ley 7/2007, de 12 de abril, del Estatuto básico del empleado público, Thomson/Aranzadi, Cizur Menor (Navarra), 2008.

Parada Vázouez, R., Derecho del Empleo Público, Marcial Pons, Madrid, 2007.

Parada Vázouez, R. y Fuentetaja Pastor, J., Derecho de la función pública, Thomson reuters, Civitas, Navarra, 2017.

SÁnchez Morón, M., Derecho de la Función Pública, Tecnos, Décima Edición, Madrid, 2017.

SARMIENTO LARRAURI, J. I., «Las incompatibilidades para el personal al servicio de las Administraciones Públicas», Actualidad Administrativa, núm. 41, 7 a 13 de noviembre de 1988, Págs. 2401 a 2413. 
Sarmiento Larrauri, J. I., "Comentarios a la Ley 7/2007 de 12 de abril del Estatuto Básico del Empleado Público», Actualidad Administrativa, núm. 16, Tomo 2, Quincena del 16 al 30 Septiembre de 2010, pág. 1914.

Serrano Pascual, A., El personal de las Entidades locales. Análisis de su régimen jurídico, El Consultor de los Ayuntamientos y de los Juzgados, Madrid, 1997. 